\title{
B-Cell Activity Predicts Response to Glatiramer Acetate and Interferon in Relapsing-Remitting Multiple Sclerosis
}

Sabine Tacke, MSc, Stefan Braune, MD, Damiano M. Rovituso, PhD, Tjalf Ziemssen, MD, Paul V. Lehmann, MD, Heidi Dikow, MSc, Arnfin Bergmann, MD, and Stefanie Kuerten, MD, PhD

Neurol Neuroimmunol Neuroinflamm 2021;8:e980. doi:10.1212/NXI.0000000000000980

\section{Abstract}

\section{Objective}

We investigated the predictive value of the enzyme-linked immunospot technique (ELISPOT) in identifying patients with relapsing-remitting multiple sclerosis (RRMS) who will respond to treatment with glatiramer acetate (GA) or interferon- $\beta$ (IFN- $\beta$ ), based on the brain-reactive B-cell activity of peripheral blood cells.

\section{Methods}

In this retrospective, cross-sectional, real-world multicenter study, we identified patients with RRMS in the NeuroTransData MS registry and stratified them based on their documented treatment response (relapse-free in the first 12 months of treatment) to GA or IFN- $\beta$. The GA group comprised 73 patients who responded to GA and 35 nonresponders. The IFN- $\beta$ group comprised 62 responders to IFN- $\beta$ and 37 nonresponders. Patients with previous or current therapy affecting B-cell activity were excluded. We polyclonally stimulated mononuclear cells from peripheral blood samples (collected after participant selection) and investigated brainreactive B-cell activity after incubation on brain tissue lysate-coated ELISPOT plates. Validity metrics of the ELISPOT testing results were calculated (Python 3.6.8) in relation to the clinical responsiveness in the 2 treatment groups.

\section{Results}

The ELISPOT B-cell activity assay showed a sensitivity of 0.74 , a specificity of 0.76 , a positive predictive value of 0.78 , a negative predictive value of 0.28 , and a diagnostic OR of 8.99 in predicting clinical response to GA vs IFN- $\beta$ therapy in patients with RRMS.

\section{Conclusion}

Measurement of brain-reactive B-cell activity by ELISPOT provides clinically meaningful predictive probabilities of individual patients' treatment response to GA or IFN- $\beta$. The assay has the potential to improve the selection of optimal first-line treatment for individual patients with RRMS.

\section{Classification of Evidence}

This study provides Class II evidence that in patients with RRMS, the brain reactivity of their peripheral-blood $B$ cells predicts clinical response to GA and IFN- $\beta$.
Correspondence

Dr. Kuerten

stefanie.kuerten@uni-bonn.de 


\section{Glossary}

ARR = annualized relapse rate; Bcl-2 = B-cell lymphoma 2; CDP = confirmed disability progression; EDSS = Expanded Disability Status Scale; ELISPOT = enzyme-linked immunospot technique; FBS = fetal bovine serum; GA = glatiramer acetate; IFN- $\beta$ = interferon- $\beta$; Ig = immunoglobulin; JNK = c-Jun N-terminal kinase; NTD = NeuroTransData; PBMC = peripheral blood mononuclear cell; PBS = phosphate-buffered saline; ROC = receiver operating characteristic; RPMI = Roswell Park Memorial Institute; RRMS = relapsing-remitting MS.

In most patients, multiple sclerosis (MS) initially presents with a relapsing-remitting MS (RRMS) course, characterized by an autoreactive $\mathrm{T}$ - and $\mathrm{B}$-cell response against CNS myelin. ${ }^{1}$ Therapy aims to achieve long-lasting stability without evidence of disease activity. ${ }^{2}$ However, the choice of first-line disease-modifying therapy (DMT) is by trial and error, rather than personalized, data-driven, benefit-risk assessment. ${ }^{3}$

The myelin basic protein analog glatiramer acetate $(\mathrm{GA})^{4-7}$ and the immune modulator interferon- $\beta$ (IFN- $\beta$ ) are among the DMTs most commonly administered at the time of diagnosis. In animal studies, GA competed with myelin antigens for presentation to $T$ cells and induced a beneficial shift in the effector T-cell profile; this remains to be demonstrated in patients. GA is also thought to remodel the B-cell compartment composition and influences B-cell cytokine and immunoglobulin ( $\mathrm{Ig}$ ) secretion, restoring dysregulated B-cell function. ${ }^{9}$ IFN- $\beta$ appears to increase expression of anti-inflammatory molecules, while downregulating proinflammatory cytokines. IFN- $\beta$ may also reduce trafficking of inflammatory cells across the blood-brain barrier and increase neuronal survival and repair. ${ }^{10}$ No direct effect of IFN- $\beta$ on B cells has been reported.

To support personalized treatment decisions in RRMS, we developed a blood-based enzyme-linked immunospot technique (ELISPOT) assay of brain-reactive B-cell activity. ${ }^{11,12}$ A positive test predicted treatment response to GA; absence of B-cell activity indicated IFN- $\beta$ responsiveness. ${ }^{13}$ As the initial trial involved a small patient cohort at a single site, we undertook this multicenter study to validate use of the assay to predict response/nonresponse to GA and IFN- $\beta$ in patients with RRMS.

\section{Methods}

This was a retrospective, real-world, multicenter study of crosssectional data from patients with RRMS. Using data collected from German outpatients with RRMS, we investigated clinical outcomes with GA and IFN- $\beta$ therapy administered for up to 12 months in relation to the brain-reactive B-cell activity of patients' peripheral blood cells.

\section{Primary Research Question}

Does the ELISPOT assay for brain reactivity of peripheral blood B cells provide a valid method for prediction of the clinical response of a patient with RRMS to GA or IFN- $\beta$ ? This study provides class II evidence for the validity of this method.

\section{Data Source}

The study used pseudonymized and pooled clinical data from patients with RRMS in the German NeuroTransData (NTD) MS registry database (for more details, see appendix e-1, links. lww.com/NXI/A450).

\section{Standard Protocol Approvals, Registrations, and Patient Consents}

The data acquisition and management protocol was approved by the ethics committees of the Bavarian and North Rhine Medical Boards (Bayerische Landesärztekammer, June 14, 2012; Ärztekammer Nordrhein, April 25, 2017). Informed consent was obtained from all patients. The study protocol was approved by the ethics committee of the Carl Gustav Carus University Hospital, Dresden, Germany (approval number EK 523122016).

\section{Study Population}

We identified 4 groups of adult patients with RRMS retrospectively (index therapy initiated 2001-2018) in the NTD MS registry: (1) patients who responded to GA treatment (Copaxone; TEVA, Ulm, Germany) (GA responders); (2) patients who did not respond to GA treatment (GA nonresponders); (3) patients who responded to IFN- $\beta$ treatment (IFN- $\beta 1$ la: Avonex [Biogen, Munich, Germany], Rebif [Merck, Darmstadt, Germany]; IFN- $\beta 1$ b: Betaferon [Bayer, Leverkusen, Germany], Extavia [Novartis, Nuremberg, Germany]) (IFN- $\beta$ responders); and (4) patients who did not respond to IFN- $\beta$ treatment (IFN- $\beta$ nonresponders). Patients were stratified as responders if they were relapse free in the first 12 months of treatment and as nonresponders if treatment was discontinued by their treating physician due to lack of efficacy, defined as any of relapse activity; clinically meaningful Expanded Disability Status Scale (EDSS) progression; worsening MRI findings; or progression of clinical disability not associated with relapse. Patients were included if they had received or were receiving GA or IFN- $\beta$ and had regular follow-up visits documented for $\geq 12$ months after index therapy initiation. Patients receiving previous or current treatment affecting B-cell function (anti-CD20 antibodies [e.g., rituximab and ocrelizumab], alemtuzumab, fingolimod, and daclizumab) were excluded.

\section{ELISPOT Testing}

ELISPOT testing was used to determine the presence in patients' blood of B cells producing IgG reactive against human brain tissue. After patients were identified in the database, peripheral venous blood samples were collected in lithium- 
heparinized tubes and diluted (1:1) in Dulbecco's phosphatebuffered saline (PBS) (Sigma, Schnelldorf, Germany), stored overnight at room temperature, and shipped to the testing laboratory at the Institute of Anatomy and Cell Biology, Friedrich-Alexander-Universität Erlangen-Nürnberg, Germany.

Peripheral blood mononuclear cells (PBMCs) were isolated by Biocoll $(1.077 \mathrm{~g} / \mathrm{mL}$; Merck Millipore, Darmstadt, Germany) density-gradient centrifugation.

For polyclonal stimulation of $\mathrm{B}$ cells, we cultured PBMCs for 96 hours at $37^{\circ} \mathrm{C}$ and $7 \% \mathrm{CO}_{2}$ at a density of $3 \times 10^{6}$ cells $/ \mathrm{mL}$ in Roswell Park Memorial Institute (RPMI)-1640 medium containing L-glutamine (Merck Millipore), 10\% fetal bovine serum (FBS; Life Technologies, Darmstadt, Germany), 100 $\mathrm{IU} / \mathrm{mL}$ penicillin and $0.1 \mathrm{mg} / \mathrm{mL}$ streptomycin (Sigma), 15 $\mathrm{ng} / \mathrm{mL}$ interleukin-2 (PeproTech, Hamburg, Germany), $2.5 \mu \mathrm{g} / \mathrm{mL}$ of the synthetic Toll-like receptor $7 / 8$ agonist R-848 (Enzo Life Sciences, Farmingdale, NY), and $1 \mu \mathrm{M}$ $\beta$-mercaptoethanol (Sigma). ELISPOT plates (Merck Millipore) were coated overnight at $4^{\circ} \mathrm{C}$ with $30 \mu \mathrm{g} / \mathrm{mL}$ human brain whole-tissue lysate (Novus Biologicals, Littleton, $\mathrm{CO}$ ), $10 \% \mathrm{FBS}$ as negative control, or $10 \mu \mathrm{g} / \mathrm{mL}$ mouse anti-human kappa IgG1 (SouthernBiotech, Birmingham, AL) as positive control. Plates were washed with PBS and nonspecific binding sites blocked with $10 \%$ FBS for 2 hours at room temperature. Stimulated cells were plated in triplicate at a density of $1 \times 10^{6}$ cells/well and incubated for 26 hours at $37^{\circ} \mathrm{C}$ and $7 \% \mathrm{CO}_{2}$ in RPMI-1640 supplemented with $10 \% \mathrm{FBS}, 100 \mathrm{IU} / \mathrm{mL}$ penicillin, and $0.1 \mathrm{mg} / \mathrm{mL}$ streptomycin. Plates were washed with PBS containing $0.025 \%(\mathrm{v} / \mathrm{v})$ Tween-20 and then incubated with the biotinylated anti-human IgG monoclonal antibody MT78/145 (Mabtech, Nacka Strand, Sweden). Spots were developed using alkaline phosphatase-conjugated streptavidin and Vector Blue substrate (Vector Laboratories, Burlingame, $\mathrm{CA}$ ), and the number of spots counted on an ImmunoSpot Series 6 Analyzer (Cellular Technology Limited, Shaker Heights, $\mathrm{OH}$ ). Samples were considered to be positive when the mean spot number was $>4.5 .^{11}$

\section{Statistical Analysis}

Descriptive statistics were calculated for demographic and clinical characteristics of each patient group. Annualized relapse rate (ARR) was calculated for patients individually. We estimated time to relapse and time to 3-month EDSSconfirmed disability progression (CDP) using Kaplan-Meier curves for each patient stratum. Statistical analyses used the pandas (pandas.pydata.org/pandas-docs/stable/reference/ api/pandas.DataFrame.describe.html) and lifelines (lifelines.readthedocs.io/en/latest/) data and survival analysis tools written in the Python programming language (version 3.6.8).

For analysis of predictive test performance and test validity, the following statistical parameters were calculated for patient groups receiving GA or IFN- $\beta$, and for both groups together, based on the proportions of patients in each group being correctly identified-or not-as responders or nonresponders: positive and negative predictive values, sensitivity, specificity, false-positive and false-negative rates, true-positive and true-negative rates, negative and positive likelihood ratios, and the diagnostic OR. CIs for sensitivity, specificity, and accuracy were calculated with the exact Clopper-Pearson method; those for likelihood ratios used the Log method; those for predictive values used standard logit intervals. Validity metrics were calculated using Python 3.6.8 (Python Software Foundation, Available at python.org).

\section{Data Availability}

The data underlying the findings of this study are available to qualified investigators on reasonable request.

\section{Results}

\section{Patient Characteristics}

In total, 207 patients with RRMS (140 female and 67 male) were identified from the NTD MS database as having received either GA $(n=108)$ or IFN- $\beta(n=99)$ as index therapy. Overall, 135 patients $(65.2 \%)$ responded to index therapy, either GA (73/108 patients, $67.6 \%)$ or IFN- $\beta$ (62/99 patients, $62.6 \%)$. The demographics and clinical characteristics of the cohorts were similar at the start of therapy (table 1).

As defined by the inclusion criteria, responders had no relapses on index therapy within the first 12 months after treatment initiation (table 1). Patients responding to either treatment showed a small improvement in mean EDSS total score within 12 months. In contrast, the mean EDSS total score remained unchanged in patients failing to respond to GA within 12 months and deteriorated slightly in patients not responding to IFN- $\beta$. Time-to-relapse analysis demonstrated a clearly favorable course in the patient strata responding to either GA or IFN- $\beta$ for up to 4 years (figure 1A). In the analysis of time to 3 -month EDSS CDP, patients in the GA and IFN- $\beta$ responder groups experienced considerably less frequent EDSS worsening than those in the nonresponder groups, not only during the first 12 months but also long term (figure 1B).

In GA nonresponders, the reason for treatment failure leading to discontinuation of GA within the first 12 months was documented by the treating physicians as relapse activity $34 \%$ (12 of 35 patients), new MRI activity 23\% (8 patients), worsening of clinical disability $37 \%$ (13 patients), and disease progression not associated with relapse $6 \%$ ( 2 patients). In IFN- $\beta$ nonresponders, the proportions of patients were $35 \%$ (13 of 37 patients), $22 \%$ (8 patients), $35 \%$ (13 patients), and $8 \%$ (3 patients), respectively.

\section{ELISPOT Testing and Predictive Capabilities}

ELISPOT results were positive in 54 GA responders and 27 IFN- $\beta$ nonresponders ( $73.6 \%$ of this combined population) and negative in 28 GA nonresponders and 46 IFN- $\beta$ responders (76.3\% of this combined population) (figure e-1, links.lww.com/NXI/A452, shows representative ELISPOT 
Table 1 Patient Baseline Characteristics at Initiation of Index Treatment With Disease-Modifying Drugs (GA or IFN- $\beta$ ) and Clinical Course on Treatment, Stratified by Response to Treatment

\begin{tabular}{|c|c|c|c|c|}
\hline Characteristic & $\begin{array}{l}\text { GA responder } \\
(n=73)\end{array}$ & $\begin{array}{l}\text { GA nonresponder } \\
(\mathrm{n}=35)\end{array}$ & $\begin{array}{l}\text { IFN }-\beta \text { responder } \\
(n=62)\end{array}$ & $\begin{array}{l}\text { IFN- } \beta \text { nonresponder } \\
(\mathrm{n}=37)\end{array}$ \\
\hline Female sex, $n(\%)$ & $53(72.6)$ & $23(65.7)$ & $38(61.3)$ & $26(70.3)$ \\
\hline Age, mean (SD), y & $37.7(10.1)$ & $36.9(8.9)$ & $36.6(9.2)$ & $37.9(13.5)$ \\
\hline $\begin{array}{l}\text { Time from first symptom to index date, mean } \\
\text { (SD), y }\end{array}$ & $6.3(8.6)^{a}$ & $7.6(7.4)$ & $5.0(6.7)$ & $4.6(5.8)$ \\
\hline $\begin{array}{l}\text { Time from diagnosis of MS to index date, mean } \\
\text { (SD), } y\end{array}$ & $5.1(6.8)$ & $5.1(5.9)$ & $3.0(5.4)$ & $3.2(5.0)$ \\
\hline ARR 12 mo before index date, mean (SD) & $0.6(0.6)$ & $0.6(0.6)$ & $0.9(0.7)$ & $0.9(1.3)$ \\
\hline Number of DMTs before index DMT, mean (SD) & $0.7(1.1)$ & $0.7(1.0)$ & $0.2(0.5)$ & $0.7(1.3)$ \\
\hline Duration of index therapy, mean (SD), mo & $63.6(42)$ & $65.7(48.4)$ & $69.7(36.0)$ & $34.9(24.1)$ \\
\hline $\begin{array}{l}\text { ARR within the first } 12 \text { mo on index therapy, } \\
\text { mean (SD) }\end{array}$ & $0(0)$ & $0.5(1.0)$ & $0(0)$ & $0.6(1.0)$ \\
\hline \multicolumn{5}{|l|}{ EDSS, median (range) } \\
\hline At index date & $2(0-6)^{b}$ & $2(0-4)^{c}$ & $2(0-4)^{d}$ & $2(0-6)^{e}$ \\
\hline 6 mo after index date & $1.5(0-5.5)^{f}$ & $1.2(0-4.5)^{g}$ & $1(0-4.5)^{\mathrm{h}}$ & $1.8(0-6)^{i}$ \\
\hline 12 mo after index date & $1(0-5.5)^{j}$ & $1.5(0-4.5)^{\mathrm{k}}$ & $1(0-4)^{\prime}$ & $2(0-6)^{\mathrm{m}}$ \\
\hline
\end{tabular}

Abbreviations: ARR = annualized relapse rate; DMT = disease-modifying therapy; EDSS = Expanded Disability Status Scale; GA = glatiramer acetate; IFN- $\beta=$ interferon- $\beta$.

Index date: date of initiation of index treatment; responder: freedom from relapse activity within the first 12 months of GA or IFN- $\beta$ treatment; nonresponder: treatment failure on GA or IFN- $\beta$ therapy (see text).

${ }^{a} n=72$.

${ }^{\mathrm{b}} \mathrm{n}=58$.

${ }^{c} n=24$.

${ }^{d} \mathrm{n}=53$.

$\mathrm{e}^{\mathrm{n}}=28$.

$f_{n}=50$.

$\mathrm{g}_{\mathrm{n}}=20$.

${ }^{\mathrm{h}} \mathrm{n}=44$.

$\mathrm{i} n=26$.

${ }^{\mathrm{i}} \mathrm{n}=52$.

${ }^{k} \mathrm{n}=19$.

' $\mathrm{n}=50$.

$m_{n}=20$.

wells illustrating the 4 different responder types). The hypothesis of the study expected positive evidence of B-cell activity in GA responders and IFN- $\beta$ nonresponders and no evidence of brain-related B-cell activity in GA nonresponders and IFN- $\beta$ responders. The strong performance of the ELISPOT test as classifier for responder/nonresponder is demonstrated in the receiver operating characteristic (ROC) curves (figure 2), which show the true-positive vs falsepositive rate of the prediction for a threshold mean spot number of 4.5. The accuracy can be derived from the area under the ROC as 0.72 for prediction of GA responders, 0.67 for IFN- $\beta$ responders, and 0.70 for the overall prediction, which reflects the study hypothesis.

\section{ELISPOT Validity}

The validity of the ELISPOT test as a predictor of individual treatment response to GA or IFN- $\beta$ was robust (table 2 ), with low false-positive and false-negative rates $(0.20-0.26$ and $0.26-0.27$, respectively), sensitivity of $0.73-0.74$, specificity of
0.74-0.80, high positive likelihood ratios $(2.86-3.70)$, and low negative likelihood ratios (0.33-0.36). The diagnostic OR was highest for potential GA responders (11.37); however, the diagnostic OR was also high for IFN- $\beta$ responders (7.76) and for both groups together (8.99). These advantageous metrics are reflected in the clinical course of the patients where the selected treatment corresponded with the hypothesized brain-specific B-cell activity. Patients treated with GA who had positive B-cell activity and patients treated with IFN $-\beta$ who had negative B-cell activity experienced less relapse activity (figure 3A) and less 3-month CDP (figure 3B) than patients for whom treatment selection and ELISPOT results did not match the hypothesis. These differences in clinical outcome were sustained for more than 5 years.

\section{Discussion}

Information regarding group-level responses to treatment obtained from randomized controlled trials in patients with 
A. Time to Relapse

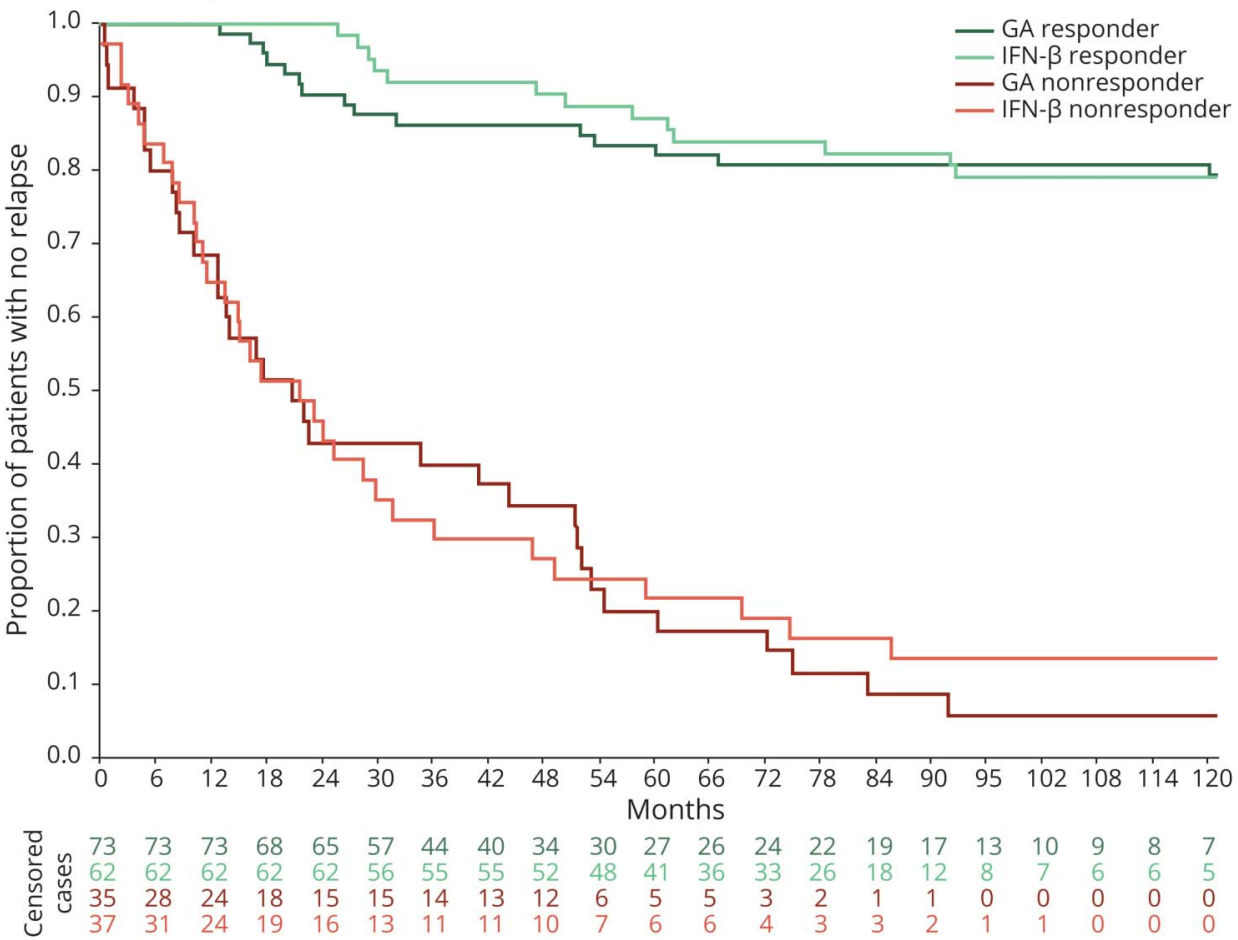

B. Time to CDP (3M)
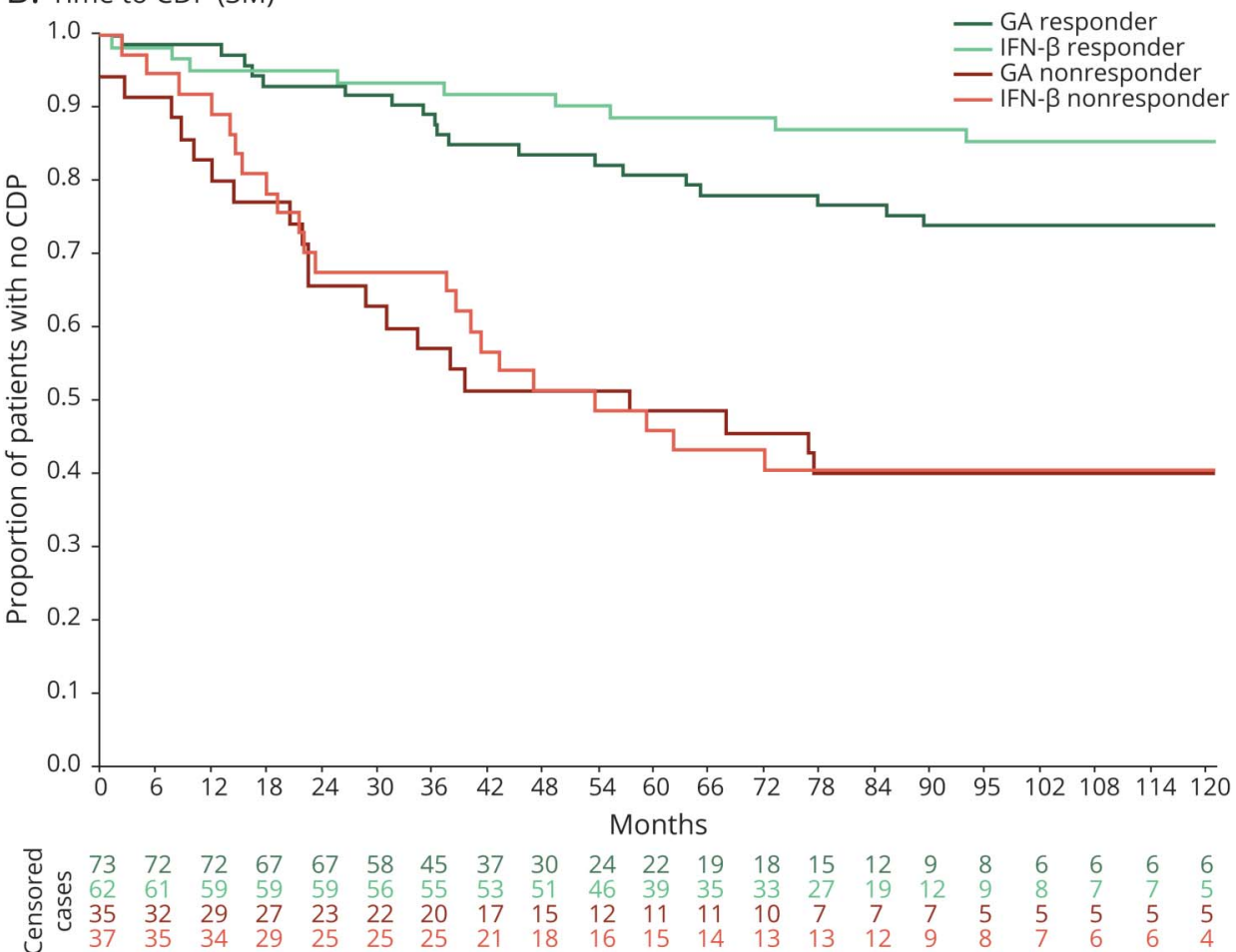

\begin{abstract}
Kaplan-Meier curves for patient strata defined by treatment response: responders defined by freedom from relapse within first 12 months of treatment with GA or IFN- $\beta$; nonresponders/failure defined as treatment failure on GA or IFN- $\beta$ therapy (see text). Patient numbers indicate the number of patients within 3 months before and after the time indicated. $\mathrm{CDP}=$ confirmed disability progression; EDSS = Expanded Disability Status Scale; $\mathrm{GA}=$ glatiramer acetate; IFN- $\beta=$ interferon- $\beta$.
\end{abstract}

RRMS has limited usefulness for personalized treatment decisions in daily practice. ${ }^{14}$ Currently, there is no alternative to the trial-and-error paradigm of treatment allocation, ${ }^{3}$ whereby the individual patient undergoes several therapy switches, with selection based on patients' and doctors' preferences, and the patient's life situation, until a suitable treatment is found. Likewise, in the later course of MS, if treatments fail to control disease activity, switching paradigms are dominated by risk considerations rather than comparative-effectiveness data. With expanding options to treat $\mathrm{RRMS}^{15-18}$ and 
Figure 2 Receiver Operating Characteristic Curves for Enzyme-Linked Immunospot Technique Test Results in (A) GATreated Patients, (B) IFN- $\beta$-Treated Patients, and (C) Combined for GA- and IFN- $\beta$-Treated Patients

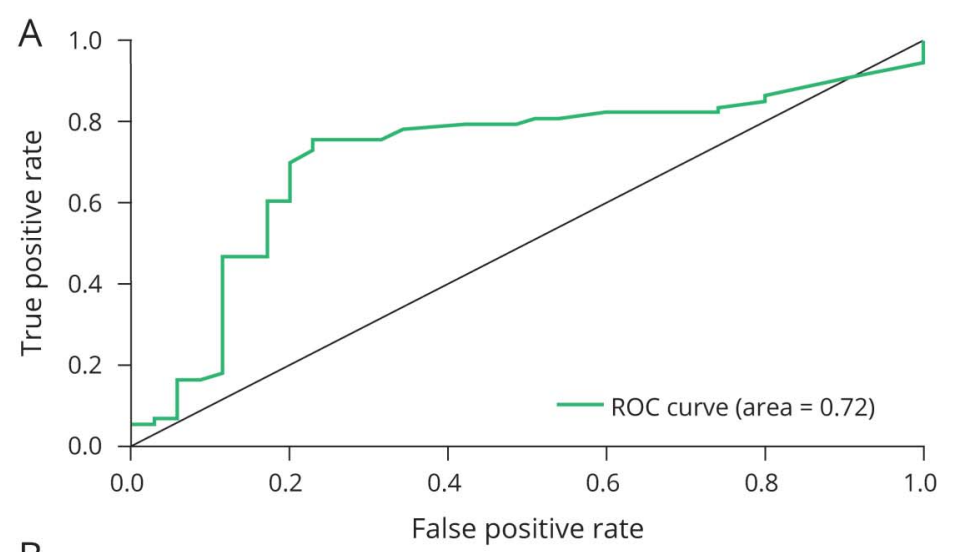

\begin{tabular}{|c|c|c|}
\hline & \multicolumn{2}{|c|}{ Condition } \\
\hline & $\begin{array}{c}\mathrm{GA} \\
\text { responder }\end{array}$ & $\begin{array}{c}\mathrm{GA} \\
\text { nonresponder }\end{array}$ \\
\hline $\begin{array}{l}\text { Positive for B-cell activity } \\
\text { (correct for responder) }\end{array}$ & 54 & 7 \\
\hline $\begin{array}{l}\text { Negative for B-cell activity } \\
\text { (incorrect for responder) }\end{array}$ & 19 & 28 \\
\hline
\end{tabular}

$$
\text { B }
$$

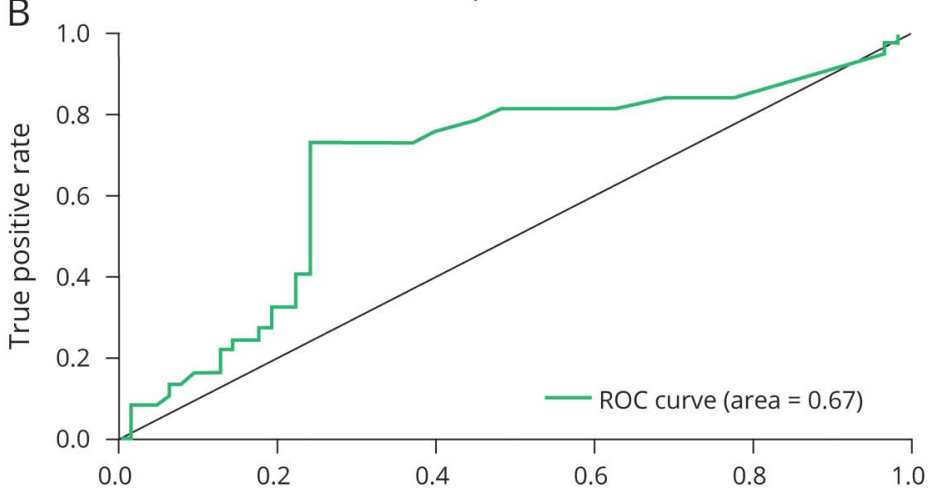

False positive rate

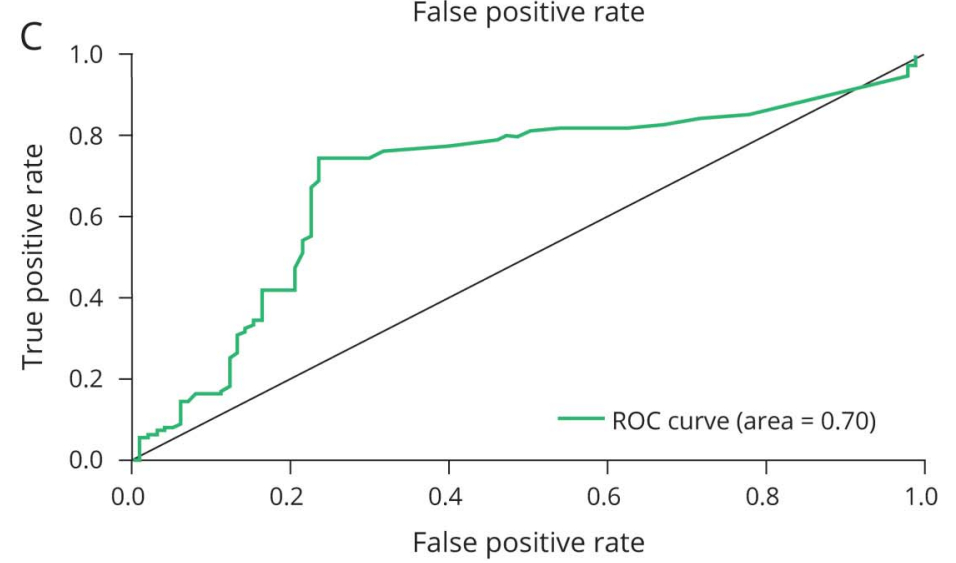

\begin{tabular}{|c|c|c|c|}
\hline & \multicolumn{2}{|c|}{ Condition } \\
\hline & & $\begin{array}{l}\text { IFN- } \beta \\
\text { responder }\end{array}$ & $\begin{array}{c}\text { IFN- } \beta \\
\text { nonresponder }\end{array}$ \\
\hline$\frac{ \pm}{\vec{v}}$ & $\begin{array}{l}\text { Positive for B-cell activity } \\
\text { (incorrect for responder) }\end{array}$ & 16 & 27 \\
\hline 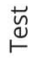 & $\begin{array}{l}\text { Negative for B-cell activity } \\
\text { (correct for responder) }\end{array}$ & 46 & 10 \\
\hline
\end{tabular}

The tables are the confusion matrices for a positive-outcome threshold of 4.5 spots. The study expected positive evidence of brain-related B-cell activity in GA responders and IFN- $\beta$ nonresponders, and no evidence of B-cell activity in GA nonresponders or IFN- $\beta$ responders. Responder: freedom from relapse activity within the first 12 months of GA or IFN- $\beta$ treatment; nonresponder: treatment failure on GA or IFN- $\beta$ therapy (see text). GA = glatiramer acetate; IFN- $\beta=$ interferon- $\beta ; \mathrm{ROC}=$ receiver operating characteristic curve.

growing awareness of the benefits of early effective treatment, there is increasing demand for data-driven, validated, personalized treatment-decision algorithms to enable an effective and economic allocation of the most suitable drug for an individual patient - which in many cases is an injectable DMT such as GA or IFN- $\beta$ - at the earliest possible time point after RRMS diagnosis.

The hypothesis underlying development of the ELISPOT assay described in this study is that in subsets of patients
RRMS develops via different auto-immunologic mechanisms, some predominantly involving $\mathrm{T}$ cell-mediated pathways, whereas in others, it is predominantly B-cell driven. The reactions to therapy of different RRMS patient subsets are therefore likely to differ. Although there is evidence that GA affects the autoreactive $\mathrm{T}$-cell response by competing with various myelin antigens for presentation to $T$ cells and thus changes the frequency of presentation, cytokine secretion pattern, and effector function of GA-specific $\mathrm{CD}^{+}$and $\mathrm{CD} 8^{+}$ $\mathrm{T}$ cells, ${ }^{8}$ there are several lines of evidence showing that GA 
Table 2 Validity Metrics for Predictive Performance Characteristics of Enzyme-Linked Immunospot Technique Testing

\begin{tabular}{llll}
\hline & GA & IFN- $\beta$ & GA and IFN- $\beta$ \\
\hline Positive predictive value & $0.89(0.66-1.16)$ & $0.63(0.41-0.91)$ & $0.78(0.62-0.97)$ \\
\hline Negative predictive value & $0.40(0.24-0.63)$ & $0.82(0.60-1.09)$ & $0.28(0.19-0.40)$ \\
\hline Sensitivity & $0.74(0.62-0.84)$ & $0.73(0.56-0.86)$ & $0.74(0.64-0.82)$ \\
\hline Specificity & $0.80(0.63-0.92)$ & $0.74(0.62-0.84)$ & $0.76(0.67-0.84)$ \\
\hline False-positive rate & $0.20(0.08-0.41)$ & $0.26(0.15-0.42)$ & $0.24(0.15-0.36)$ \\
\hline False-negative rate & $0.26(0.16-0.41)$ & $0.27(0.13-0.50)$ & $0.26(0.18-0.38)$ \\
\hline Positive likelihood ratio & $3.70(1.88-7.27)$ & $2.86(1.78-4.50)$ & $3.11(2.14-4.51)$ \\
\hline Negative likelihood ratio & $0.33(0.21-0.50)$ & $0.36(0.21-0.63)$ & $0.35(0.25-0.48)$ \\
\hline Diagnostic OR & $11.37(4.27-30.27)$ & $7.76(3.09-19.52)$ & $8.99(4.78-16.90)$ \\
\hline
\end{tabular}

Abbreviations: GA = glatiramer acetate; IFN- $\beta$ = interferon- $\beta$.

Data are values and $95 \%$ Cls.

also has a direct effect on B cells. For example, a study in patients with MS showed that GA therapy remodeled the composition of the B-cell compartment and influenced B-cell cytokine secretion and Ig production. ${ }^{9}$ In an in vitro study, GA improved $\mathrm{B}$ cell-dependent control of $\mathrm{T}$ cells' immune responses and was shown to switch the memory $B$ cells known to contribute to the $\mathrm{T}$ cell-dependent inflammatory response into B regulatory cells. ${ }^{19}$ More recently, Häusler et al. ${ }^{20}$ showed that GA treatment changed the B-cell phenotype in patients with MS. In addition, in the experimental autoimmune encephalomyelitis model, they demonstrated that GA altered the pathogenic B-cell-T-cell interaction. ${ }^{20}$ In contrast, IFN- $\beta$ has been shown to suppress inflammatory responses in patients with MS by controlling the secretion of pro- and anti-inflammatory cytokines, suppressing T-cell activation, inducing differentiation of neural stem cells to oligodendrocytes, and preventing migration of activated immune cells through the blood-brain barrier, while no direct effect on $\mathrm{B}$ cells has been demonstrated for IFN- $\beta .^{10}$ It therefore seemed reasonable to investigate the possibility that individual patients likely to respond to GA could be identified by the involvement of pathogenic B-cell activity in their disease.

Biomarker studies typically use ELISAs, which are cost-efficient, easy to handle, and hence popular when developing highthroughput tests. Although ELISAs are well suited to detecting antibodies against linear epitopes, such as peptide antigens, antibodies that are pathogenic in vivo are generally directed against conformational epitopes. Although protein ELISAs seem desirable, synthesis of the protein in its in vivo conformation and molecular structure is technically highly challenging and cost-intensive. ELISPOT has been used to guide clinical practice in other therapeutic areas, such as in the diagnosis of active tuberculosis. ${ }^{21,22}$

The ELISPOT technique used in this study is highly effective in detecting immune responses at the single-cell level, providing sensitivity superior to that of ELISAs and other immunemonitoring approaches. ${ }^{23}$ In combination with polyclonal stimulation, our assay provides information for an individual patient on the memory B-cell pool, which may be recruited at any given time to participate in disease reactivation. ${ }^{12}$ We have previously demonstrated that the presence of brain-specific $\mathrm{B}$ cells in blood as measured by ELISPOT is indicative of an MS diagnosis ${ }^{11}$ and is associated with a higher risk of relapse ${ }^{12}$ and a positive treatment response to $\mathrm{GA}^{13}$ (see appendix e-2, links. lww.com/NXI/A451, for further information). Whereas our earlier studies were single center with small patient cohorts, here we present data from a multicenter trial and provide proof of the feasibility of the logistics to perform the ELISPOT test on samples from patients nationally.

The protocol definitions for response and nonresponse enabled discrimination of the clinical course between strata regarding relapse activity and 3-month CDP (figure 1). Although the definition of responder was constrained to freedom from relapse within the first 12 months of treatment, analyses of time to relapse and time to 3-month CDP demonstrate a striking difference between responding and nonresponding patients over $>5$ years. Analysis of the validity of ELISPOT testing to predict individual treatment response is based on these clearly different clinical courses.

Our data suggest that ELISPOT-based measurements of brain-reactive $B$ cells in the blood of patients with RRMS may distinguish between GA and IFN- $\beta$ responders. Individual treatment response to either GA or IFN- $\beta$ was predicted correctly in approximately 3 of 4 patients, with values for sensitivity and specificity between 0.73 and 0.80 . In parallel, positive predictive values for all strata and negative predictive values for patients receiving IFN- $\beta$ were high. Negative predictive values for GA and for GA and IFN- $\beta$ together were lower. 
A. Time to relapse

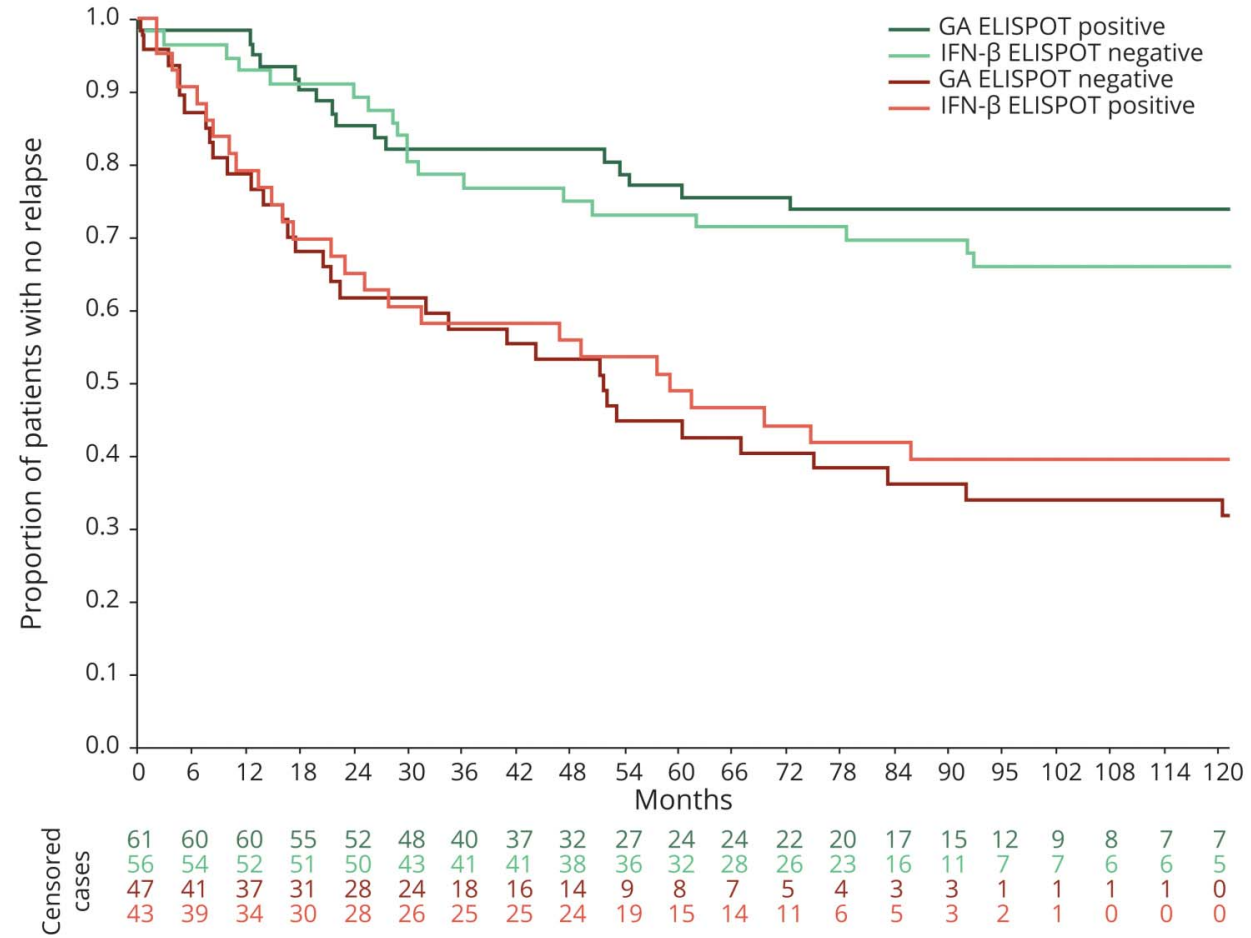

B. Time to $\operatorname{CDP}(3 M)$

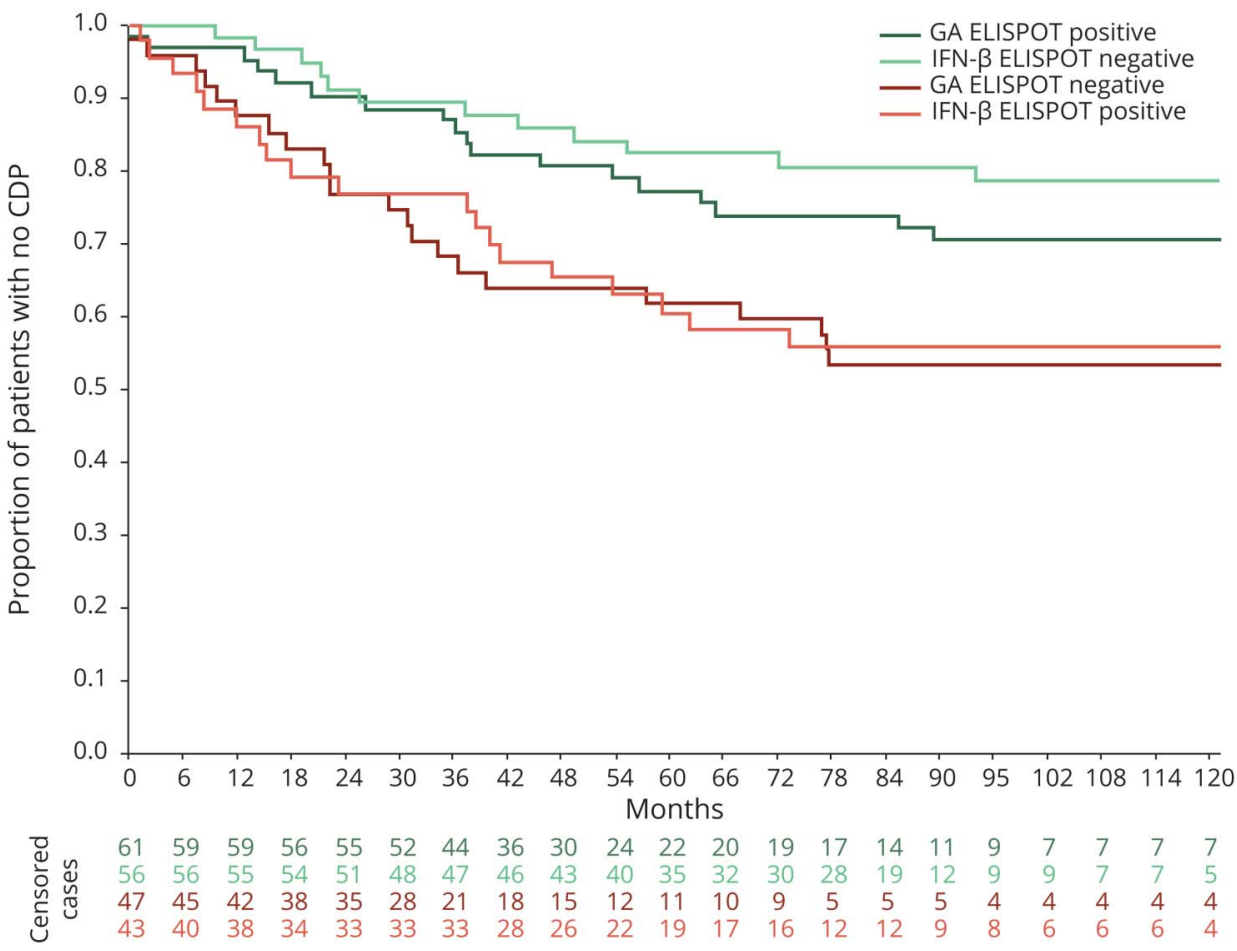

\begin{abstract}
Kaplan-Meier curves for patient strata defined by positive or negative ELISPOT results indicating presence or absence of in vivo brain-specific B-cell activity in patients on GA or IFN- $\beta$ therapy. Patient numbers indicate the number of patients within 3 months before and after the time indicated. It was hypothesized that positive B-cell activity in patients treated with GA and negative B-cell activity in patients treated with IFN- $\beta$ would be associated with better clinical outcome. CDP = confirmed disability progression; EDSS = Expanded Disability Status Scale; ELISPOT = enzyme-linked immunospot technique; $\mathrm{GA}=$ glatiramer acetate; IFN- $\beta=$ interferon- $\beta$.
\end{abstract}

The positive likelihood ratios of between 2.86 and 3.70 underline the predictive strength of the ELISPOT assay, whereas the negative likelihood ratios of between 0.33 and 0.36 indicate only a small decrease in the probability that the test result predicts the clinical course.
Based on the diagnostic OR, defined as the ratio of the odds of a true-positive test result relative to the odds of a false-positive result, this study shows the highest effectiveness of ELISPOT testing is for potential GA responders (diagnostic OR 11.37), with high values also for IFN- $\beta$ responders (7.76), and both 
groups together (8.99). These metrics reflect the robust validity of ELISPOT testing to predict responsiveness to GA or IFN- $\beta$ in patients with RRMS. This discriminative ability is mirrored in the different clinical courses of the 4 patient strata, which demonstrate better clinical outcomes-sustained for $>5$ years-in patients whose selected treatment corresponded with the hypothesized brain-specific B-cell activity.

The anti-CNS reactivity of B cells from patients with MS was confirmed in a recent study combining ELISPOT and planar protein arrays. ${ }^{24}$ Culture supernatants of polyclonally stimulated B cells from a subset of patients with MS identified by ELISPOT as having reactivity to human brain lysate were tested against a broad spectrum of myelin antigens using protein/peptide arrays. Compared with ELISPOT-negative patients and controls, ELISPOT-positive patients with MS demonstrated broader reactivity to the myelin proteins.

Heterogeneous profiles of antibody responses to the myelin proteins were seen in the patients with MS who demonstrated reactivity, but the profiles remained stable for each patient over time. In a separate study, testing of B cells found to be brain reactive by ELISPOT did not demonstrate reactivity to smallintestine lysate, confirming the tissue specificity of the response (S. Kuerten, oral communication, September 30, 2020).

Another potential approach to identifying patients' response to GA therapy has recently been published. ${ }^{25}$ This study suggested increased expression of the signaling molecules c-Jun $\mathrm{N}$-terminal kinase (JNK)1 p54 and JNK2 p54 and a decrease in the downstream expression of phosphorylated B-cell lymphoma 2 (Bcl-2) during MS relapse to be indicative of failure to respond to GA therapy. However, the study population comprised only 15 patients with RRMS and no other DMT reference group. Thus, the change in expression profiles for JNK and phosphorylated $\mathrm{Bcl}-2$ may have been reflective of disease reactivation in general and could be associated with treatment failure of any DMT.

The detection of neurofilament levels in serum and CSFwhich may be indicative of CNS tissue damage-is extensively discussed. $^{26,27}$ In patients with MS, blood neurofilament concentrations are associated with clinical and MRI-related measures of disease activity ${ }^{26,27}$ and could thus be an easily accessible biomarker of disease evolution and treatment response. However, it is unclear which technical standard is required to measure neurofilament levels most reliably, and the single-molecule array technique is expensive due to high investment costs. Also, changes in neurofilament concentrations have only been shown at the patient-cohort level; the predictive value of their measurement in individual patients remains to be demonstrated. Pharmacogenetic studies of patient responses to GA and IFN- $\beta$ have shown inconsistent results. ${ }^{28-30}$ Given the complexity of the disease and the probability that multiple mechanisms of action underlie the effects of these drugs, it is likely that a comparative, multiallele approach would be needed, requiring extensive validation in clinical trials. ${ }^{31}$
The current study corroborates the strength of the brainspecific B-cell ELISPOT for prediction of clinical response to GA and IFN- $\beta$ in individual patients with MS. This study was based on previously captured clinical data in association with a randomly timed cross-sectional blood sample for ELISPOT; thus, further research is required to develop the test as a certified biomarker for use in clinical practice. As the test results confirm treatment decisions in the majority of patients, this could provide a rationale to consider a switch from first-line therapies, based on test results in nonresponsive patients. A prospective longitudinal trial has yet to be conducted as ultimate confirmation of the clinical utility of the B-cell ELISPOT to inform treatment decisions between GA and IFN- $\beta$ on diagnosis of MS. Eventually, given the recent success of antiCD20 antibodies in MS, ELISPOT testing may also be valuable for detecting responsive patients and monitoring the success of $\mathrm{B}$ cell-active drugs. We are currently investigating the potential use of B-cell ELISPOT for prediction of clinical responsiveness to anti-CD20 and anti-CD52 antibody treatments.

Although the use of real-world data has advantages over clinical-trial data, in terms of being more representative of patient populations and physician decisions, real-world studies can be subject to a range of limitations including low internal validity, lack of quality control in data collection, and the potential for bias, which limits the interpretation of outcomes. In this study, the key limitations associated with the retrospective use of real-world data were the lack of rigor in data collection (compared with a clinical trial) and the potential for bias arising from including only cases that had sufficient documentation to meet the definition of relapse. The accuracy of the test may be further improved by taking key variables into account; such an analysis is planned in a larger sample.

Pathophysiologically, detection of brain-specific B cells in a proportion of patients with RRMS indicates the existence of MS subtypes based on B-cell activity. This is consistent with neuropathologic studies that have identified the presence of antibody and complement depositions in demyelinating brain lesions ${ }^{32}$ and of meningeal B-cell aggregates in a subset of patients with MS. ${ }^{33,34}$

\section{Acknowledgment}

The authors thank Ursula Lebherz for assistance with patient recruitment and shipment of material to the practices. Editorial assistance (technical editing of final draft) was provided by Duncan Porter and Julie Ponting of Anthemis Consulting Ltd, funded by Friedrich-Alexander-Universität.

\section{Study Funding}

The study was funded by Teva Pharmaceutical Industries Ltd, the manufacturer of Copaxone (glatiramer acetate).

\section{Disclosure}

S. Tacke reports no disclosures. S. Braune has received honoraria for clinical studies, speaker fees, and consultancy from Biogen, CSL Behring, Genzyme, Lilly, NeuroTransData, Novartis, Roche, and Teva. D.M. Rovituso reports no disclosures. 
T. Ziemssen has received reimbursements for participation in scientific advisory boards from Almirall, Bayer, Biogen, Celgene, Merck, Novartis, Sanofi, and Teva and has received speaker honoraria from Bayer, Biogen, Celgene, Genzyme, Novartis, Sanofi, and Teva and research support from Biogen, Novartis, Sanofi, and Teva. P.V. Lehmann is founder and CEO of Cellular Technology Limited, a company that focuses on ELISPOT and immune monitoring. H. Dikow reports no disclosures. A. Bergmann has received consulting fees for advisory board/speaker/other activities from NeuroTransData and for project management/clinical studies and travel expenses from Novartis and Servier. S. Kuerten reports grants from the Deutsche Forschungsgemeinschaft, Novartis, Roche, and Sanofi, all outside the submitted work, and speaker fees and consultancy honoraria during the conduct of the study from Novartis, Roche, Sanofi, and Teva. Go to Neurology.org/ $\mathrm{NN}$ for full disclosures.

\section{Publication History}

Received by Neurology: Neuroimmunology \& Neuroinflammation July 23, 2020. Accepted in final form January 12, 2021.

\section{Appendix Authors}

\begin{tabular}{lll}
\hline Name & Location & Contribution \\
\hline Sabine & Friedrich-Alexander- & $\begin{array}{l}\text { Performed experiments an } \\
\text { Tacke, MSc }\end{array}$ \\
& $\begin{array}{l}\text { Universität Erlangen- } \\
\text { Nürnberg, Germany }\end{array}$ & $\begin{array}{l}\text { management and revised } \\
\text { the manuscript for } \\
\text { intellectual content }\end{array}$ \\
\end{tabular}

\begin{tabular}{lll}
\hline Stefan & NeuroTransData, Neuburg & Contributed to trial design \\
Braune, & an der Donau, Germany & and management; \\
MD & & conducted statistical \\
& analysis; drafted parts of the \\
& manuscript; and was \\
& responsible for funding \\
& acquisition
\end{tabular}

\begin{tabular}{ll}
\hline Damiano & Friedrich-Alexander- \\
M. & Universität Erlangen- \\
Rovituso, & Nürnberg, Germany \\
PhD &
\end{tabular}

Performed experiments and contributed to study management and revised the manuscript for intellectual content

\begin{tabular}{ll}
\hline Tjalf & University Hospital Carl \\
Ziemssen, & Gustav Carus, Technische \\
MD & Universität Dresden, \\
& Germany
\end{tabular}

\begin{tabular}{ll}
\hline Paul V. & Cellular Technology \\
Lehmann, & Limited, Shaker Heights, \\
MD & $\mathrm{OH}$
\end{tabular}

Contributed to study management and revised the manuscript for intellectual content

Provided intellectual input throughout the course of the study and revised the manuscript for intellectual content

\begin{tabular}{lll}
\hline Heidi & NeuroTransData, Neuburg \\
Dikow, MSc & an der Donau, Germany & $\begin{array}{l}\text { Performed statistical } \\
\text { analyses and revised the } \\
\text { manuscript for intellectual } \\
\text { content }\end{array}$ \\
\hline
\end{tabular}

\begin{tabular}{lll}
\hline $\begin{array}{l}\text { Arnfin } \\
\text { Bergmann, }\end{array}$ & NeuroTransData, Neuburg & $\begin{array}{l}\text { Contributed to study design } \\
\text { and management; }\end{array}$ \\
MD & & $\begin{array}{l}\text { responsible for funding } \\
\text { acquisition; and revised the } \\
\text { manuscript for intellectual } \\
\text { content }\end{array}$ \\
& \\
\hline
\end{tabular}

Appendix (continued)

\begin{tabular}{|c|c|c|}
\hline Name & Location & Contribution \\
\hline $\begin{array}{l}\text { Stefanie } \\
\text { Kuerten, } \\
\text { MD, PhD }\end{array}$ & $\begin{array}{l}\text { Friedrich-Alexander- } \\
\text { Universität Erlangen- } \\
\text { Nürnberg, Germany; now } \\
\text { at Anatomisches Institut/ } \\
\text { Neuroanatomie, } \\
\text { Universität Bonn, } \\
\text { Germany }\end{array}$ & $\begin{array}{l}\text { Performed experiments; } \\
\text { contributed to study design } \\
\text { and management; } \\
\text { responsible for funding } \\
\text { acquisition; supervised the } \\
\text { experiments; and wrote the } \\
\text { manuscript }\end{array}$ \\
\hline
\end{tabular}

\section{References}

1. Dendrou CA, Fugger L, Friese MA. Immunopathology of multiple sclerosis. Nat Rev Immunol 2015;15:545-558.

2. Giovannoni G, Turner B, Gnanapavan S, Offiah C, Schmierer K, Marta M. Is it time to target no evident disease activity (NEDA) in multiple sclerosis? Mult Scler Relat Disord 2015;4:329-333.

3. Grossman I, Knappertz V, Laifenfeld D, et al. Pharmacogenomics strategies to optimize treatments for multiple sclerosis: insights from clinical research. Prog Neurobiol 2017;152:114-130.

4. Teitelbaum D, Meshorer A, Hirshfeld T, Arnon R, Sela M. Suppression of experimental allergic encephalomyelitis by a synthetic polypeptide. Eur J Immunol 1971;1: 242-248.

5. Webb C, Teitelbaum D, Arnon R, Sela M. In vivo and in vitro immunological crossreactions between basic encephalitogen and synthetic basic polypeptides capable of suppressing experimental allergic encephalomyelitis. Eur J Immunol 1973;3:279-286.

6. Webb C, Teitelbaum D, Herz A, Arnon R, Sela M. Molecular requirements involved in suppression of EAE by synthetic basic copolymers of amino acids. Immunochemistry 1976;13:333-337.

7. Teitelbaum D, Aharoni R, Sela M, Arnon R. Cross-reactions and specificities of monoclonal antibodies against myelin basic protein and against the synthetic copolymer 1. Proc Natl Acad Sci USA 1991;88:9528-9532.

8. Ziemssen T, Schrempf W. Glatiramer acetate: mechanisms of action in multiple sclerosis. Int Rev Neurobiol 2007;79:537-570.

9. Ireland SJ, Guzman AA, O'Brien DE, et al. The effect of glatiramer acetate therapy on functional properties of $B$ cells from patients with relapsing-remitting multiple sclerosis. JAMA Neurol 2014;71:1421-1428.

10. Kieseier BC. The mechanism of action of interferon- $\beta$ in relapsing multiple sclerosis. CNS Drugs 2011;25:491-502.

11. Kuerten S, Pommerschein G, Barth SK, et al. Identification of a B cell-dependent subpopulation of multiple sclerosis by measurements of brain-reactive B cells in the blood. Clin Immunol 2014;152:20-24.

12. Hohmann C, Milles B, Schinke M, et al. Categorization of multiple sclerosis relapse subtypes by B cell profiling in the blood. Acta Neuropathol Commun 2014;2:138.

13. Rovituso DM, Duffy CE, Schroeter M, et al. The brain antigen-specific B cell response correlates with glatiramer acetate responsiveness in relapsing-remitting multiple sclerosis patients. Sci Rep 2015;5:14265.

14. Claflin SB, Broadley S, Taylor BV. The effect of disease modifying therapies on disability progression in multiple sclerosis: a systematic overview of meta-analyses. Front Neurol 2019;9:1150.

15. Oh J, O'Connor PW. Novel and imminently emerging treatments in relapsing- remitting multiple sclerosis. Curr Opin Neurol 2015;28:230-236.

16. Capra R, Cordioli C, Rasia S, Gallo F, Signori A, Sormani MP. Assessing long-term prognosis improvement as a consequence of treatment pattern changes in MS. Mult Scler 2017;23:1757-1761

17. Lizak N, Lugaresi A, Alroughani R, et al. Highly active immunomodulatory therapy ameliorates accumulation of disability in moderately advanced and advanced multiple sclerosis. J Neurol Neurosurg Psychiatry 2017;88:196-203.

18. Brown JWL, Coles A, Horakova D, et al. Association of initial disease-modifying therapy with later conversion to secondary progressive multiple sclerosis. JAMA 2019;321:175-187.

19. Amrouche K, Pers JO, Jamin C. Glatiramer acetate stimulates regulatory B cell functions. J Immunol 2019;202:1970-1980.

20. Häusler D, Hajiyeva Z, Traub JW, et al. Glatiramer acetate immune modulates B-cell antigen presentation in treatment of MS. Neurol Neuroimmunol Neuroinflamm 2020;7:e698. doi: 10.1212/NXI.0000000000000698.

21. Hofland RW, Thijsen SF, van Lindert AS, et al. Positive predictive value of ELISpot in BAL and pleural fluid from patients with suspected pulmonary tuberculosis. Infect Dis (Lond) 2017;49:347-355.

22. Della Bella C, Spinicci M, Grassi A, et al. Novel M. tuberculosis specific IL-2 ELISpot assay discriminates adult patients with active or latent tuberculosis. PLoS One 2018; 13:e0197825

23. Tary-Lehmann M, Hamm CD, Lehmann PV. Validating reference samples for comparison in a regulated ELISPOT assay. In: Prabhakar U, Kelley M, editors. Validation of Cell-Based Assays in the GLP Setting: A Practical Guide, 1st ed. Chichester UK: John Wiley \& Sons, Ltd; 2008:127-146.

24. Kuerten S, Lanz TV, Lingampalli N, et al. Autoantibodies against central nervous system antigens in a subset of B cell-dominant multiple sclerosis patients. Proc Natl Acad Sci USA 2020;117:21512-21518. 
25. Anselmo F, Tatomir A, Boodhoo D, et al. JNK and phosphorylated Bcl-2 predict multiple sclerosis clinical activity and glatiramer acetate therapeutic response. Clin Immunol 2020;210:108297.

26. Kuhle J, Kropshofer H, Haering DA, et al. Blood neurofilament light chain as a biomarke of MS disease activity and treatment response. Neurology 2019;92:e1007-e1015.

27. Kuhle J, Plavina T, Barro C, et al. Neurofilament light levels are associated with longterm outcomes in multiple sclerosis. Mult Scler 2020;26:1691-1699.

28. Tsareva E, Kulakova O, Boyko A, Favorova O. Pharmacogenetics of multiple sclerosis: personalized therapy with immunomodulatory drugs. Pharmacogenet Genomics 2016;26:103-115.

29. Kulakova OG, Tsareva EY, Lvovs D, Favorov AV, Boyko AN, Favorova OO. Comparative pharmacogenetics of multiple sclerosis: IFN- $\beta$ versus glatiramer acetate. Pharmacogenomics 2014;15:679-685.
30. Mahurkar S, Suppiah V, O'Doherty C. Pharmacogenomics of interferon beta and glatiramer acetate response: a review of the literature. Autoimmun Rev 2014;13: 178-186.

31. Coyle PK. Pharmacogenetic biomarkers to predict treatment response in multiple sclerosis: current and future perspectives. Mult Scler Int 2017;2017:6198530.

32. Lucchinetti C, Brück W, Parisi J, Scheithauer B, Rodriguez M, Lassmann H. Heterogeneity of multiple sclerosis lesions: implications for the pathogenesis of demyelination. Ann Neurol 2000;47:707-717.

33. Magliozzi R, Howell O, Vora A, et al. Meningeal B-cell follicles in secondary progressive multiple sclerosis associate with early onset of disease and severe cortical pathology. Brain 2007;130:1089-1104.

34. Howell OW, Reeves CA, Nicholas R, et al. Meningeal inflammation is widespread and linked to cortical pathology in multiple sclerosis. Brain 2011;134:2755-2771. 


\title{
Neurology \\ Neuroimmunology \& Neuroinflammation
}

\author{
B-Cell Activity Predicts Response to Glatiramer Acetate and Interferon in \\ Relapsing-Remitting Multiple Sclerosis \\ Sabine Tacke, Stefan Braune, Damiano M. Rovituso, et al. \\ Neurol Neuroimmunol Neuroinflamm 2021;8; \\ DOI 10.1212/NXI.0000000000000980
}

This information is current as of March 11, 2021

Updated Information \&

Services

References

Subspecialty Collections

Permissions \& Licensing

Reprints including high resolution figures, can be found at:

http://nn.neurology.org/content/8/3/e980.full.html

This article cites 33 articles, 5 of which you can access for free at: http://nn.neurology.org/content/8/3/e980.full.html\#\#ref-list-1

This article, along with others on similar topics, appears in the following collection(s):

Autoimmune diseases

http://nn.neurology.org//cgi/collection/autoimmune_diseases

Class II

http://nn.neurology.org//cgi/collection/class_ii

Multiple sclerosis

http://nn.neurology.org//cgi/collection/multiple_sclerosis

Information about reproducing this article in parts (figures,tables) or in its entirety can be found online at:

http://nn.neurology.org/misc/about.xhtml\#permissions

Information about ordering reprints can be found online: http://nn.neurology.org/misc/addir.xhtml\#reprintsus

Neurol Neuroimmunol Neuroinflamm is an official journal of the American Academy of Neurology.

Published since April 2014, it is an open-access, online-only, continuous publication journal. Copyright

Copyright (C) 2021 The Author(s). Published by Wolters Kluwer Health, Inc. on behalf of the American

Academy of Neurology.. All rights reserved. Online ISSN: 2332-7812.

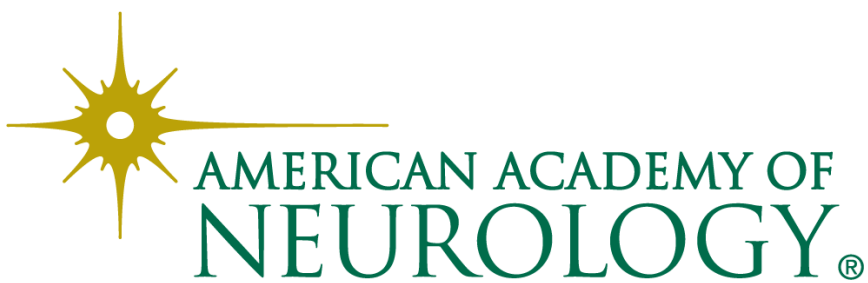

